\title{
Towards Seismic Design of Nonstructural Elements: Italian Code-Compliant Acceleration Floor Response Spectra
}

\author{
Beatrice Chichino (D), ${ }^{1}$ Simone Peloso $(D),{ }^{1}$ Davide Bolognini $\left(D,{ }^{1}\right.$ Claudio Moroni $\left(\mathbb{D},{ }^{2}\right.$ \\ Daniele Perrone $(\mathbb{D})^{3,4}$ and Emanuele Brunesi $\left.{ }^{1}\right)^{1}$
}

${ }^{1}$ European Centre for Training and Research in Earthquake Engineering, Pavia, Italy

${ }^{2}$ Italian Department of Civil Protection (DPC), Rome, Italy

${ }^{3}$ University School for Advanced Studies IUSS Pavia, Pavia, Italy

${ }^{4}$ University of Salento, Lecce, Italy

Correspondence should be addressed to Emanuele Brunesi; emanuele.brunesi@eucentre.it

Received 16 July 2021; Revised 7 September 2021; Accepted 24 October 2021; Published 9 November 2021

Academic Editor: Qian Chen

Copyright (c) 2021 Beatrice Chichino et al. This is an open access article distributed under the Creative Commons Attribution License, which permits unrestricted use, distribution, and reproduction in any medium, provided the original work is properly cited.

\begin{abstract}
Seismic risk reduction of a building system, meant as primary building structure and nonstructural elements (NSEs) as a whole, must rely upon an adequate design of each of these two items. As far as NSEs are concerned, adequate seismic design means understanding of some basic principles and concepts that involve different actors, such as designers, manufacturers, installers, and directors of works. The current Italian Building Code, referred to as NTC18 hereinafter, defines each set of tasks and responsibilities in a sufficiently detailed manner, rendering now evident that achieving the desired performance level stems from a jointed contribution of all actors involved. Bearing in mind that seismic design is nothing else than proportioning properly seismic demand, in terms of acceleration and/or displacement, and the corresponding capacity, this paper gives a synthetic and informative overview on how to evaluate these two parameters. To shed some light on this, the concept of acceleration floor response spectrum (AFRS) is firstly brought in, along with basics of building structure-NSEs interaction, and is then deepened by means of calculation methods. Both the most rigorous method based on nonlinear dynamic simulations and the simplified analytical formulations provided by the NTC18 are briefly discussed and reviewed, trying to make them clearer even to readers with no structural/earthquake engineering background because, as a matter of fact, NSEs are often selected by architects and/or mechanical or electrical engineers. Lastly, a simple case study, representative of a European code-compliant five-storey masonryinfilled reinforced concrete frame building, is presented to examine differences between numerical and analytical AFRS and to quantify accuracy of different NTC18 procedures.
\end{abstract}

\section{Introduction}

Several scientific studies concerning nonstructural elements (NSEs) underline and recognise not only that most of the construction costs of a building are represented by NSEs but also that these are the cause of the main economic losses and service interruptions when an earthquake occurs, even in case of a low-intensity one [1-7]. The relevance of NSEs should become clear by simply bearing in mind the effects of any past earthquake events, even more so when attention is focussed on the behaviour of critical structures (e.g., hospitals, schools, and barracks) or production facilities; see Figure 1, for instance. Several research studies (e.g., [8-15]) can also be brought to readers' attention for potential seismic vulnerabilities associated with NSEs housed in critical facilities, such as hospitals or industrial plants.

The poor seismic performance that characterises NSEs is a direct consequence of the lack of attention given to these so-called "nonstructural" elements by both regulators and designers. Indeed, unlike structures whose seismic design has been regulated for decades, for NSEs the situation is certainly not as uniform. Targeting the optimal seismic 


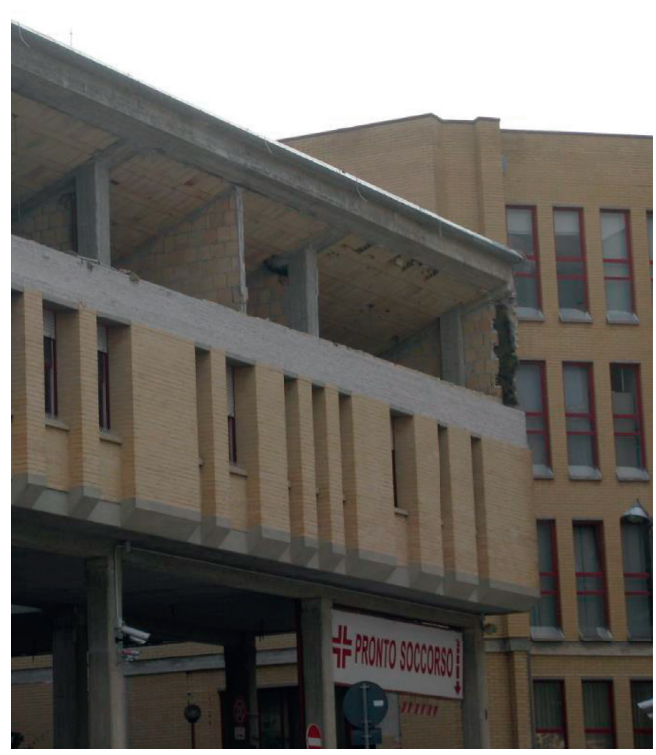

(a)

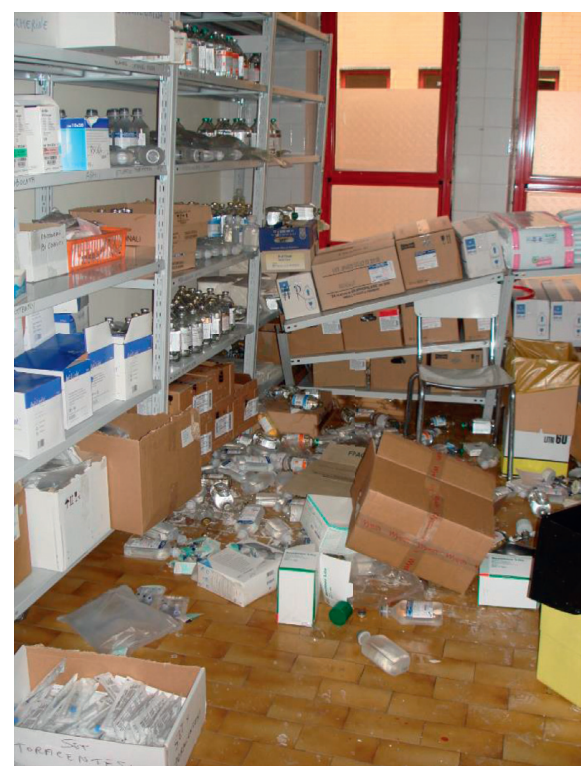

(b)

Figure 1: Effect of the L'Aquila earthquake (2009) on the Coppito Hospital: (a) falling off the infills on the entry of an emergency room and (b) overturning of shelves in the hospital pharmacy.

performance of NSEs can be pursued by means of design, which however is rarely standardised [16], or through the implementation of mainly empirical solutions suggested by guidelines (e.g., FEMA E-74 [17] and DPC [18]), which are often the result of postevent field observations. Although the prediction and control of the seismic behaviour of NSEs were deemed too complex tasks to be addressed until a few decades ago, the situation has drastically changed over the years and is vastly different nowadays so that engineering the problem could not be postponed further.

It is worthy of mention that some product-specific standards already exist for a few types of NSEs (e.g., UNI EN 81-77: 2019 [19]). Such codes or standards, however, are not mandatory, so it is not infrequent that manufacturers choose not to apply them, aiming at less performant products that are cheaper and, somehow, better respond to market demands/needs. Nevertheless, the benefits that would derive both from the codification of dedicated design approaches and from the systematic adoption of seismic qualification procedures, either experimental or numerical or both, for NSEs would be evident if safety issues were taken as seriously as the economic aspects, or even if generalised costs were taken as the proper parameter to quantify budgetary issues. These two steps are the only means to ensure uniform performance for the building system as a whole.

Within such context, the work described in this paper sheds some light on aspects of design and qualification of NSEs, focussing mainly on the seismic input to which these elements are (and should be) subjected and the methods to estimate such input. Concepts surrounding the acceleration floor response spectrum (AFRS) idea are firstly reviewed, briefly, and the three methods implemented in Italian Building Code [20], henceforth called NTC18, for the calculation of AFRS are then scrutinised. A simple numerical example involving the complete finite element (FE) modelling and nonlinear time-history analysis (NLTHA) of a single case-study five-storey, three-bay reinforced concrete (RC) frame building, extracted from a wide masonry-infilled $\mathrm{RC}$ frame building portfolio [7], is finally presented to allow readers to compare the results obtained from the most accurate/rigorous method and the simplified methodologies recommended in the NTC18 [20]. Regardless of whether the following point would reduce or not the responsibility of designers and manufacturers, it is worth noting that the correct seismic behaviour of any NSE type could not ignore the respect of all installation details, and requirements needed to ensure the boundary conditions assumed at the design stage are actually met. Despite the importance of such aspect, it will neither be treated nor deepened in this paper, which is chiefly concerned with design and demand evaluation related issues.

\section{Seismic Design of NSEs}

In a very general and synthetic way, the designer must check that for each and every load combinations considered, demand does not exceed capacity of the item to be designed or that associated with the specific damage mechanism of interest. Nonetheless, the evaluation of these two parameters (i.e., demand and capacity) is nontrivial when dealing with earthquake-induced actions on NSEs or plant equipment, and when, depending on the case, forces, displacements, and/or ductility should necessarily be considered. Performance objectives, related to capacity, are also envisaged.

Some concepts useful for the calculation of these two parameters are briefly clarified in what follows. Readers may note that reference will be made only to NSEs, whereas the treatment could easily be extended to plant equipment, the 
latter being possibly idealised as an ensemble of NSEs of different kind. For what concerns the Italian Building Code [20], the only difference between the design of NSEs and equipment in an industrial plant is the need to comply with the functionally requirement at the operability limit state (OLS), which adds up to the stability requirement at the life safety limit state (i.e., acronymised hereon as "SLV" to comply with Italian nomenclature provided in the code [20]). The first one is required only for plants' equipment, whilst the second one, namely, the stability requirement, is required both for NSEs and for plants' equipment, as per NTC18 [20].

2.1. Seismic Demand on NSEs. Unlike other load conditions (such as those involving gravity loads), seismic actions could be regarded as actions induced by a low-probability/highconsequence (LPHC) event and at the current state of knowledge, their intensity can only be estimated with a certain level of approximation and by referring to a certain probability of occurrence. In spite of the fact that a so limited-in-accuracy approach is something one has to necessarily settle for (at least, when compared with other load conditions), the calculation of seismic-induced actions is still complex and involves aspects of geology, seismology, physics, mathematics, and engineering, with significant implications of probability theory.

Additionally, probability and uncertainties are pivotal aspects. Based on the knowledge where earthquake events of the recent past occurred and on the interpretation of traces that historical earthquakes have left on the Earth's crust, it is only possible to estimate where an earthquake is most likely to occur and not exactly where it will occur. In light of this, it is not possible to assess when a seismic event will occur; time, in earthquake engineering applications, is a parameter that can only be related to the intensity of an earthquake. The longer the period considered (return period $T_{\mathrm{R}}$ ), the greater the probability of having an earthquake of a certain intensity or, again, the greater the intensity of the earthquake that could occur. Most regrettably, the available mathematical models do not currently allow any better than this. The above are just a couple of examples that tell how much conditioned the problem is by uncertainty and probability, although many others can actually be found. The construction materials' strength, as well as the building geometries or ground stratigraphy at a given site, are just a few other examples of well-known parameters that are inherently affected by uncertainty.

As mentioned above, to undertake a seismic design check, it is necessary to know the actions that an earthquake or a set of earthquakes generate on one or more NSEs, which could ideally be installed onto any floor of any building located kilometres away from the hypocentre. Everything that is physically present between the latter and the NSE of interest contributes to the change in the waves that the earthquake generates, thus having an effect on the seismic actions whose intensity should be estimated.

Put extremely simply, the release of the deformation energy accumulated over the years or decades causes seismic waves to generate and propagate. The energy, initially distributed in a certain range of frequencies, spreads and is partly dissipated. Some vibration frequencies may be damped, losing some of the energy they carry. On the other hand, other frequencies may be amplified, as schematically shown in Figure 2. Once the waves reach the base of a building, they excite it and make it vibrate. In turn, the building, characterised by its own distribution of stiffness and mass, vibrates and modifies the waves that propagate throughout it, from foundations to the NSE of interest. Likewise, the building structure alters the balance of energy amongst different frequencies, amplifying earthquake effects around the structural frequencies and filtering the energy carried by the other frequencies. When seismic actions reach the floor wherein the NSE is assumed to be installed, they indeed have characteristics other than those corresponding to the hypocentre signal or the one at the base of the building. The intensity of the seismic demand acting on a particular NSE also depends on its dynamic characteristics.

The most straightforward way to represent seismic actions is through a certain accelerogram (i.e., acceleration time history of a specific point decomposed into the three main directions). Unfortunately, such a representation is as informative as event-specific, which helps gather why a response spectrum is the most frequently used tool in earthquake engineering applications for a general and synthetic representation of seismic input. An acceleration, or a displacement, response spectrum is the maximum response to a predefined input motion of a family of single degree-of-freedom systems as a function of their natural frequencies and at a specified damping ratio.

With reference to the example depicted in Figure 3, a generic system (either this be a building or a NSE), with a vibration period $\mathrm{T}^{*}$ equal to $0.4 \mathrm{~s}$ (i.e., a frequency $f=1$ / $\mathrm{T}=2.5 \mathrm{~Hz}$ ), and subjected to the seismic input represented by the response spectra in Figure 3, will experience a maximum acceleration $S_{\mathrm{A}}\left(\mathrm{T}^{*}\right)$ of $0.4 \mathrm{~g}$ (about $4 \mathrm{~m} / \mathrm{s}^{2}$ ), and the maximum displacement of its centre of gravity $S_{\mathrm{D}}\left(\mathrm{T}^{*}\right)$ will equal $0.09 \mathrm{~m}$.

Due to a variety of parameters and physical mechanisms/ effects that come into play, and with a view to simplify design efforts, the NTC18 [20] define how to calculate the response spectrum (both for the entire building and for NSE of any sort) to be used for design. For the former case, use will be made of the ground response spectrum, corresponding to a given construction site and chosen $T_{\mathrm{R}}$, whilst for the latter case, use will be made of the AFRS, calculated for the floor where the case-study NSE is assumed to be installed. Figure 4 provides a schematic showing how the characteristics of the ground acceleration spectrum (as a function of the structural period $T_{\mathrm{S}}$ ) in conjunction with those of the structure produce the AFRS (as a function of the nonstructural period $\mathrm{T}_{\mathrm{NSE}}$ ). In general, the most recent methodologies to calculate AFRS, including the methodology proposed by NTC18 [20], assume that the AFRS are mainly affected by the following parameters: (1) dynamic filtering offered by the vibration modes of the supporting structures, (2) damping characteristics of the NSEs, and (3) inelastic response of the supporting structure. 

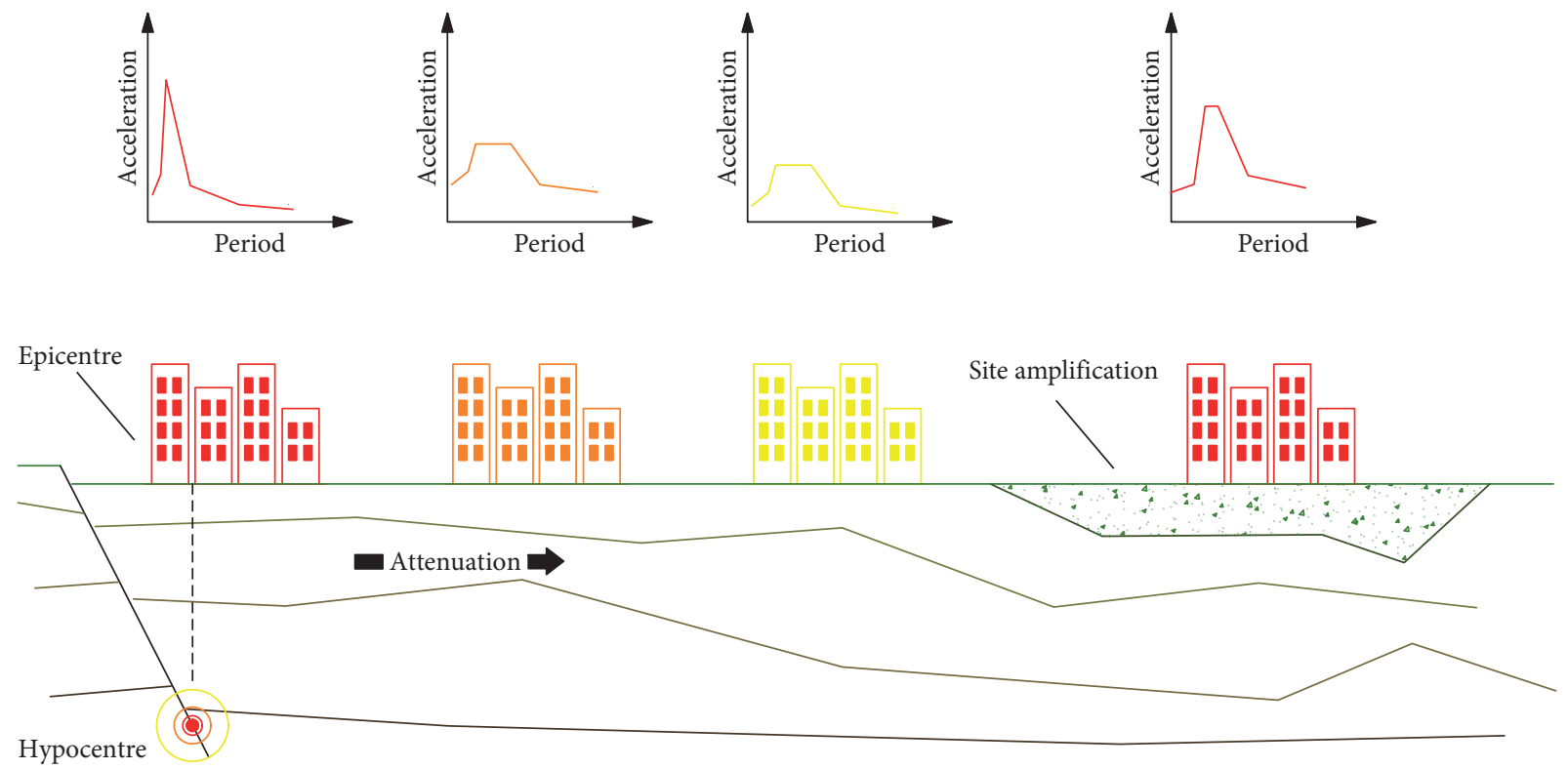

Figure 2: Propagation of seismic waves.

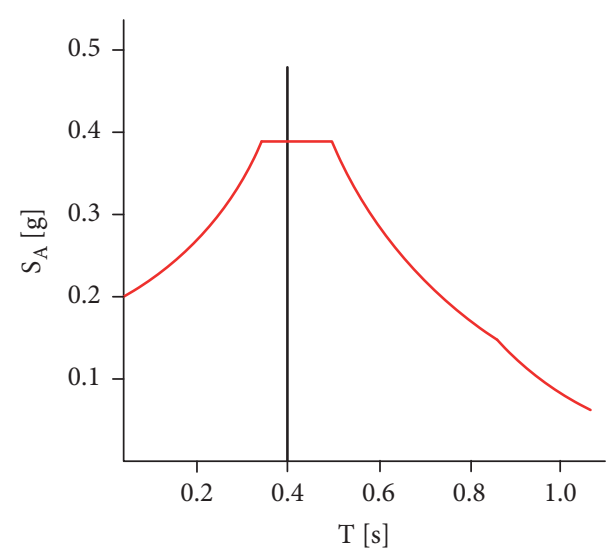

(a)

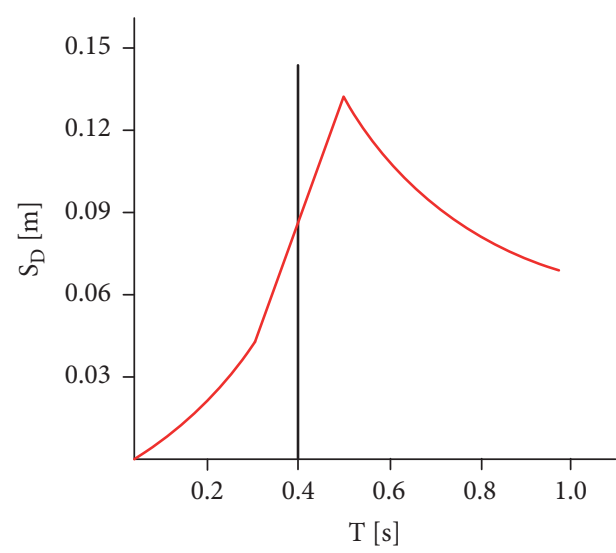

(b)

Figure 3: Acceleration (a) and displacement (b) response spectra.

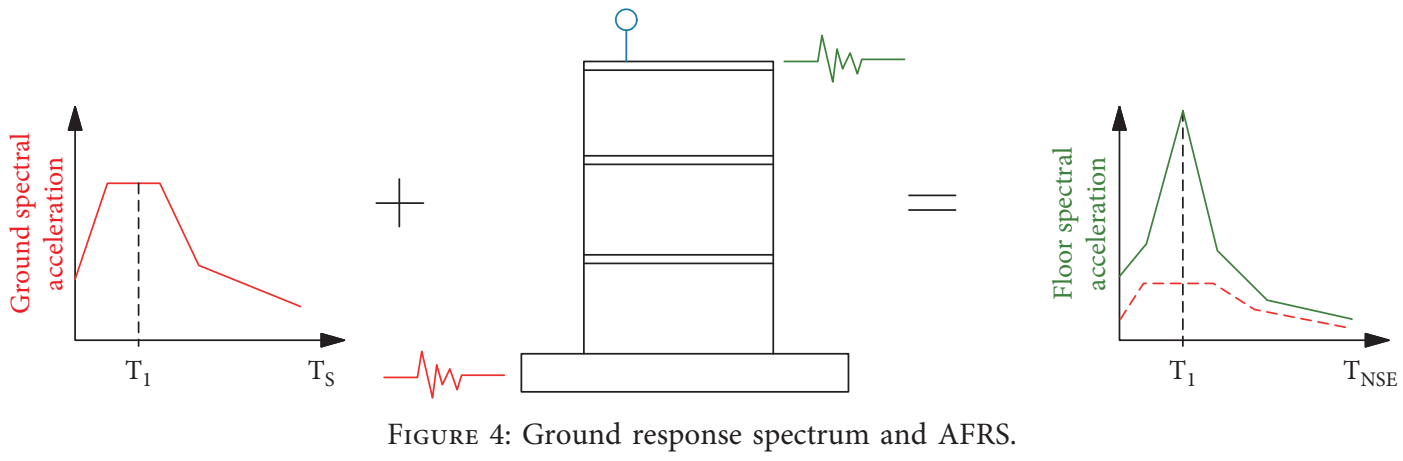

Finally, it is simply noted that the brief/basic overview proposed here by the authors can be merged with much more specific and detailed explanations of seismic demand criteria and/or formulations for acceleration-sensitive NSEs (amongst others; see [7, 12, 13, 16, 21-28]). Out of these research contributions, the authors would refer interested 
readers to Merino et al. [16], who proposed a methodology for consistent floor response spectra for performance-based seismic design of NSEs, and to D'Angela et al. [28], wherein the influence of the building in terms of seismic demand on NSEs is discussed in an explicit manner, providing also a simplified formulation to account for it. It is worthy of mention also that examples of direct analysis, involving the explicit modelling of NSEs, are scarcely few and tend to be limited to specific applications [13-15].

2.2. Seismic Capacity of NSEs. The design of NSEs is very frequently carried out directly by NSE producers and manufacturers, considering only and exclusively (i) their primary function, (ii) load conditions associated with their specific use, and (iii) the gravity loads, which in turn means that abnormal actions such as those resulting from a LPHC event (e.g., an earthquake) are not at all considered. At the regulatory level, there can be situations for which product-specific regulations/standards (i) simply omit the case of an earthquake occurring, (ii) provide provisions that apply exclusively to cases other than seismic loading, or (iii) give quite scarce and purely qualitative indications on how to tackle the issue of seismic design. Even when product standards are available, the treatment of seismic design is rather poor and relies upon scarcely few qualitative indications. In the vast majority of cases, these standards (UNI EN 13964:2014 [29], to name one) contain few and nonexhaustive sentences that make reference to other more general building codes for the calculation of the seismic actions to be applied and state, in a rather terse and vague way, that capacity should be high enough to prevent earthquakeinduced damage or failure. Not surprisingly, performance that should be granted for different levels of seismic intensity/shaking is ignored or untreated. As a consequence of this, several past seismic events, even low-intensity ones, have repeatedly shown lack of seismic performance for different NSE types, highlighting how the collapse of NSEs can trigger both risks for building occupants as well as important service interruptions and huge economic, direct and indirect, losses $[1,3,6,12,17-19]$. The importance and value of NSEs being now acknowledged, regulatory boards, and bodies have intensified codification efforts, prompting the release of documents and standards dedicated to classes of NSEs or specific elements (see, e.g., $[17,20,29-31])$. The latter come as a result of experimental and numerical research efforts undertaken, mostly, over the last decade (amongst others; see [32-37]).

For what concerns the Italian context, NTC18 [20] defines (also) for both NSEs and plants, the minimum performance targets. At clause 7.2.3 of the NTC18 [20], NSEs are defined as those elements whose stiffness and mass significantly influence the structural response and those which are equally significant for the safety of occupants, even without influencing the structural response. The same clause identifies also professional roles/actors assigning them very precise duties and responsibilities, such that the role-dutiesresponsibilities chain could be established, for each phase from design to installation. Roughly translated, $\$ 7.2 .3$ in the NTC18 [20] recommends that when the NSE of interest is built on site, the designer of the structure has to identify demand on the NSE and has to design its capacity in accordance with formulations of proven validity, whereas verifying the correct execution is a task of the construction manager. When, instead, the NSE is assembled on site, it is the task of the designer to identify the demand, whilst the task of supplier and/or installer is to provide elements and connections with adequate capacity, and that of the construction manager is to verify the correct assembly.

The NTC18 [20] code assigns suppliers/producers with the responsibility to ensure ad hoc performance of an on-site assembled NSE. Then, if the attribution of this task is clear, it is not equally clear, for each and every case, to manufacturers, installers, and designers how to coordinate each other and act to satisfy this requirement/need. Concerning this specific aspect, strictly compulsory regulations are sometimes lacking or missing, although some international standards can be found, either general or dedicated to specific types of NSEs, which allow the seismic capacity of these components to be evaluated.

Depending on the NSE type, the standards allow assuming different approaches, which can either be alternative to one another or can be taken as complementary/auxiliary. In general, these methods may be based on numerical analysis, or qualification through experimental testing or verifications through past field observation (whenever the same, or at least similar, NSEs had been subjected to earthquake-induced actions during one or more past events).

\section{Turning Ground into the Floor Response Spectrum}

Herein, it is systematically exposed how to derive the AFRS, taken as the minimum target to be used either for seismic qualification or for design. The described procedures summarise a sequence of steps to be followed to determine the AFRS and start from the choice of both construction site and reference limit state. Account is also given of the dynamic characteristics of the primary structure, wherein the considered NSE is installed. In particular, the complete and most accurate procedure consists of the following:

Choosing the construction site

Identifying the limit state of interest

Calculating the input ground motion spectrum (target spectrum)

Developing a numerical model of the primary (building) structure

Undertaking dynamic analysis, possibly in nonlinear fashion

Extracting output obtained from dynamic analysis (floor acceleration time histories)

Calculating the AFRS from floor acceleration time histories 
Evaluating the required response spectrum (RRS), at a given floor, the latter being used for the seismic qualification

For the sake of completeness, the simplified methods proposed by the Commentary of the Italian Building Code "Circolare Applicativa NTC18" [38] will be scrutinised in the following subsections. Should structural regularity allow assuming a simplified formulation, the above-mentioned procedure reduces to the following:

Choice of the construction site

Identification of the limit state of interest

Calculation of the input ground motion spectrum (target spectrum)

Development of a numerical model of primary (building) structure

Eigenvalue analysis

Evaluation of RRS for seismic qualification by means of the a priori selected simplified formulation

Whenever the seismic qualification (e.g., [31]) is to be carried out, regardless of whether the latter is based on experimental or numerical methods, it is necessary to define the actions to which the NSE is subjected, and hence the actions considered NSE is to be designed or verified for. Referring to the acceleration-sensitive NSE (meaning those installed on the extrados or intrados of a floor and not connected to different floors) and to the context of experimental qualification through dynamic testing, the seismic input to be reproduced by the shake table has to necessarily be an accelerogram. This input motion may be generated artificially, as granted by several international standards, starting from an elastic acceleration response spectrum. Given that the NSEs to qualify are usually not installed on ground but rather at any point in the structures that house them, the reference motion is that at the installation point (i.e., floor motion).

When performing a seismic qualification via shake-table testing (see, e.g., [31]), for a given floor spectrum to be used as RRS, it is possible to generate the acceleration time history needed for the testing. During the test then, it is necessary to record the acceleration time history actually imposed by the shake table and to obtain the test response spectrum (TRS) as a result of this. In theory, the latter should coincide with the RRS; as a matter of fact, this is not, and cannot be, the case, and all different standards indicate the maximum acceptable deviations between the RRS and the TRS, together with the frequency ranges over which it is important that the spectra match the regulatory requirements.

The purpose of the procedures described below is to obtain the AFRS, bearing in mind that current structural design codes, NTC18 [20] and EC8 [39,40] included, make use of the AFRS to estimate the response of a NSE installed at a given, generic height along the building. In general, the AFRS considers the following:

The characteristics of dynamic amplification of the primary structure, which typically manifest themselves around its own periods of vibration and which vary along the height of the building

The viscous and hysteretic damping, possibly mobilised when taking the ultimate limit state (ULS) as a reference, of the primary structure hosting the NSEs

The resonance effects between the primary structure and the NSEs

The viscous damping of the NSEs

The hysteretic damping of the NSEs related to plasticisation of any sort that the earthquake may cause to them

It is worthwhile to note that the reduction of spectral ordinates, generated by the plastic-hysteretic behaviour of the NSEs, should be considered only in some applications. For instance, this spectral acceleration reduction must be considered in the calculation of the maximum demand/ stresses used to size the connection system of the NSEs to the primary structure. However, in the definition of the AFRS, when intended to use as RRS for seismic qualification tests, no reduction at all must be considered because the testing already reproduces any hysteretic dissipation phenomena owing to the inelastic/plastic response of the specimen/NSE.

3.1. Calculation of AFRS through Dynamic Time History Analysis. In order to calculate the motion of a generic floor and to subsequently evaluate the corresponding AFRS, a numerical model of the structure is necessary so that dynamic time history analyses could be carried out. A balance should be sought, by the analysts, between (1) the level of detail and complexity of the FE model, with its ability to reproduce the onset and development of different nonlinear behaviour types, and (2) the likeliest response, or the type of behaviour expected during the earthquake, and the type of analysis chosen. Generally, it is envisaged that numerical models be able to capture all behaviours that involve, at least, the onset of the structural plastic response phase because of the recommendation for minimum performance imposed by the NTC18 [20], the latter being the compliance with the stability requirement for actions corresponding to the ULS.

Assuming a decision is taken, by the analysts, to not only model the primary structure but also consider its inelastic behaviour, any geometric and material nonlinearity must be considered. Two different modelling strategies may be used, depending on case-specific applications:

The former strategy is the so-called concentrated plasticity (CP) modelling, which relies upon a formulation that entails plastic hinges be located directly at the end of the beam-column elements. The inelastic behaviour is lumped only at such locations, whilst the remaining portions of beams and columns have an elastic behaviour. To calibrate these models, however, some numerical modelling skills are required since it is necessary to know how to define a priori the behaviour of plastic hinges and then to predict the type of damage mechanisms/modes, to define the moment-rotation 
interaction diagram of the hinges (along with bending moment-axial force interaction diagram), to estimate their length, and to correctly choose the hysteretic model.

The latter is the distributed plasticity (DP) approach, very often referred to as fibre modelling, which instead requires only the sectional properties/characteristics and suitable constitutive nonlinear stress-strain relationships for the materials. In spite of a higher computational burden, models of this kind do not require a priori estimation of the behaviour of structural components, even if this formulation often does not consider all possible failure mechanisms and may require offline verifications that damage modes of interest, which are all properly taken into account. More specifically, fibre modelling may entail that shear- and joint-related issues be integrated by means of specific model elements or links, which accompany the elongation of fibres.

Once the model geometry is set, the characteristics of materials, viscous damping, and distribution of masses have to be defined so that nonlinear dynamic analyses can be carried out. Although this type of analysis is certainly very demanding from modelling and computational points of view, it is deemed the most accurate method to estimate the structural response under seismic loading. The correct definition of seismic input in terms of accelerograms is of paramount importance, in addition to the correct definition of all structural model features, simply because the equations of motion are to be integrated over time. Nevertheless, once the analysis is completed, the numerical model can directly return the time history response (e.g., in terms of accelerations) at any point of the structure or rather in any structural node of the FE model. By using the floor acceleration time history, it is immediate to determine the corresponding elastic response spectrum. Such spectrum is the maximum response to a defined input motion of a family of single degree-of-freedom systems as a function of their natural frequencies and at a specified damping ratio. The latter is the basis for determining the input for whichever, numerical or experimental, seismic qualification method.

It is needless to also note that the above-mentioned numerical models, developed for nonlinear dynamic analyses, can certainly be used to evaluate the parameters that characterise the modes of vibration of the primary structure, such as the natural periods, mode shapes and transformation factors. Such parameters can be used not only to validate the numerical model, based on any experimental tests (e.g. dynamic identification, for an existing structure), but also to calculate the AFRS by adopting one of the simplified formulations proposed by the Commentary of the Italian Building Code [38].

\subsection{NTC18-Compliant Formulations for AFRS Calculation.} This section describes the simplified formulations proposed by the Commentary of the Italian Building Code [38], each of which can be used to determine analytically the AFRS as a function of (i) the accelerogram of an earthquake ground motion (or spectrum of an input ground motion) and (ii) the modal characteristics of the structure of interest. All simplified methods rely upon some assumptions that depend on the specific formulation and that must be verified by the user beforehand. These methods stem from analytical considerations and result in closed-form, easy-to-use expressions but are developed and validated using the results of a rather limited series of structural typologies and configurations. The assumptions underlying these simplified formulations limit their applicability, and the simplified methods themselves may become less reliable when approaching borderline or particular situations.

An example is the case of irregular building structures or structures with high level of energy dissipation capacity that are expected to enter the plastic phase of their response, likewise the verification of ULS for newly built/designed buildings or interventions involving existing buildings that are usually not adequate to meet current seismic provisions/ standards. Most of the simplified methods are based on modal parameters and require a numerical structural model to be developed, capable of correctly evaluating vibration periods, modal shapes, and transformation factors. For the implementation of the most general simplified methods, whenever the considered limit state makes the nonlinear structural behaviour very likely to occur, numerical models must be able to adapt the framework of pushover analysis, in such a way that a correct evaluation of reduction coefficient necessary to convert the elastic ground motion spectrum into the overdamped one could be granted. This implies that a simple linear-elastic model should turn into a structural model that takes into account material and geometric nonlinearities involved in the problem, albeit in nonlinear static fashion with advantages and drawbacks of pushover analysis. However, it is noteworthy that the reliability of obtained results could be reduced if seismic excitation is to compromise the linearity of structural response or in the presence of pronounced structural irregularities. Moreover, the simplified methods should not be used when NSEs have a significant mass and could interact and modify the seismic response of a structural system.

Hereinafter, the three simplified methods proposed by the Commentary [38] are briefly reviewed, for the sake of reproducibility of presented results and later discussion. Interested readers are directly referred to $\$ C 7.2 .3$ of the Commentary [38] for more comprehensive information and details.

\subsubsection{General Formulation: "Formulazione Generale".} For the application of the most general of the three approaches proposed in the Commentary [38], henceforth called general formulation or simply acronymised as GF, the first step is to develop a linear-elastic FE model capable of providing analysts/designers with the following modal characteristics of structure:

$T_{i}$ is the natural period of the ith mode of the structure $\varphi_{i}$ is the ith mode shape 
$\Gamma_{i}$ is the transformation factor of the ith mode of the structure

Note that the pedex $i$ indicates the considered eigenmode/value. Additionally, the equivalent viscous damping value of the NSE $\left(\xi_{a}\right)$ shall be chosen (the pedex a corresponds to nonstructural equipment in the treatment from here onwards).

For the ith eigenmode, jth floor of the supporting structure, and natural period of NSE $\left(T_{a}\right)$, the value of floor acceleration spectrum $S_{a, i j}\left(T_{a}\right)$ is determined as per

$$
S_{a, i j}\left(T_{a}\right)=\varphi_{i j} \cdot \Gamma_{i} \cdot S_{i}\left(T_{i}\right) \cdot R\left(\frac{T_{a}}{T_{i}} ; \xi_{a}\right) .
$$

The following parameters need to be introduced, in addition to the above-mentioned ones:

$S_{i}\left(T_{i}\right)$ is the ground motion spectral acceleration corresponding to the ith structural mode (normalised to gravitational acceleration $g$ and, possibly, reduced by the design behaviour factor $q$ for the building for the reference limit state).

$R=\left[\left(2 \xi_{a}\left(T_{a} / T_{i}\right)\right)^{2}+\left(1-\left(T_{a} / T_{i}\right)\right)^{2}\right]^{-\beta}$ is the dynamic amplification factor of the NSE calculated as a function of its damping $\xi_{a}$, its period $T_{a}$, and the period $T_{i}$ of the ith mode of the structure. The $\beta$ coefficient permits account of the coupling between each mode of vibration of the primary structure and the fundamental mode of the NSE.

AFRS obtained for individual modes should then be combined, for instance, by using the square root of sum of squares (SRSS) rule. It is inherent that AFRS are calculated directly from the ground acceleration spectrum. The Commentary [38] allows application of this method building upon the elastic spectrum or an overdamped one, reduced by $q$. Such reduction should reflect the amount of nonlinear behaviour activated at each specific limit state considered, instead of being simply taken as the q value assumed for the design of the structure, a value which considers energy dissipation effects inherently related to the expected behaviour at the collapse limit state (CLS). In order to estimate the likeliest reduction for the elastic acceleration spectrum, the behaviour factor should be calculated by means of a nonlinear analysis, envisaged to be dynamic so as to account for cyclic response over time. However, any sort of nonlinear analysis would partly compromise the simplicity of the floor spectrum assessment methodology.

The Commentary [38] allows accounting for a reduction of accelerations on NSEs through an a priori defined behaviour factor $q_{\mathrm{a}}$ (where values are tentatively tabulated according to the NSE; see Table C7.2.1 at clause C7.2.3 of the Commentary [38]). The latter correction of spectral ordinates is to be applied when the spectrum is meant for the design of a NSE (e.g., for the design of its anchors), but it must be omitted for the purposes of experimental seismic qualification tests. This is simply because during a test, any specimen responds according to its characteristics and the overdamping effect will be gathered as a result.

\subsubsection{Simplified Formulation: "Formulazione Semplificata".} The Commentary [38] allows the use of a second, further simplified method, therein named "formulazione semplificata" or simplified formulation (SF), which holds regardless of the considered primary structure typology. As in the previous case, this method calculates the AFRS as an SRSS combination of all modal contributions deemed significant. Different modal contributions result from different spectral ordinates of ground acceleration spectrum, depending on the modal characteristics of the structure (i.e., modal shapes and periods of vibration). Therefore, also with this formulation, it is necessary to develop a model that allows accurate eigenvalue analysis to be undertaken.

Note that the nomenclature used in this section has also followed the Commentary [38], where parameters relating to the primary structure have index $k$, whereas those relating to the NSE counterpart have no index. As reported by (2), the modal contributions to the floor response spectrum $S_{e Z}$ are expressed as functions of the period, equivalent viscous damping, and installation height of the NSE, which are denoted as $T, \xi$, and $z$, respectively:

$$
S_{e Z, k}(T, \xi, z)= \begin{cases}\frac{1.1 \xi_{k}^{-0.5} \eta(\xi) a_{Z, k}(z)}{1+\left[1.1 \xi_{k}^{-0.5} \eta(\xi)-1\right]\left(1-\left(T / a T_{k}\right)\right)^{1.6}} & \text { for } T<a T_{k}, \\ 1.1 \xi_{k}^{-0.5} \eta(\xi) a_{Z, k}(z), & \text { for } a T_{k} \leq T<b T_{k}, \\ \frac{1.1 \xi_{k}^{-0.5} \eta(\xi) a_{Z, k}(z)}{1+\left[1.1 \xi_{k}^{-0.5} \eta(\xi)-1\right]\left(\left(T / b T_{k}\right)-1\right)^{1.2}}, & \text { for } T \geq b T_{k},\end{cases}
$$

where $T_{k}$ is the natural period of kth mode of the structure with equivalent viscous damping $\xi_{k}$ and $\eta(\xi)=\sqrt{10 /(5+\xi)} \geq 0.55$ is the factor that modifies the elastic spectrum for a nonstructural damping coefficient $\xi$, different from 5\%. If the floor spectrum has to be used for qualification tests on a shake table, this coefficient must be set equal to $1 ; a$ and $b$ are coefficients that define the maximum amplification range of the floor spectrum and can 
be assumed equal to 0.8 and 1.1, respectively; $a_{Z, k}(z)$ is the contribution of the kth mode to the maximum floor acceleration, often also termed Peak Floor Acceleration (PFA) or Zero Period Acceleration (ZPA).

The Commentary [38] also indicates calculation of the parameter $a_{Z, k}(z)$ as per

$$
a_{Z, k}(z)=S_{e}\left(T_{k}, \xi_{k}\right)\left|\gamma_{k} \psi_{k}\right| \sqrt{1+0.0004 \xi_{k}^{2}}
$$

where $\gamma_{k}$ and $\psi_{k}$ are the $k$ th modal participation coefficient of primary structure and the value of the kth modal shape at height $z$, respectively.

Unlike GF, this simplified method requires that (i) the floor response spectrum be never less than the elastic ground motion spectrum and that (ii) the maximum amplification in correspondence to the vibration periods of the primary structure be capped.

This method implies that should a more accurate evaluation of floor spectrum be targeted, the secant period and modal damping must be estimated through a nonlinear static analysis. Only in this way, in fact, it is possible to limit the strong amplifications that characterise the responses of linear systems around their own period of vibration.

In case of structures with mass uniformly distributed along the height and first modal shape linear with the height (i.e., regular structures), adoption of a further simplification is allowed. In such cases, the calculation can be reduced by considering only the contribution of the first vibration mode, and the corresponding modal participation coefficient $\gamma_{1}$ may be approximated as a function of the number of floors $n$, as reported by

$$
\gamma_{1}=\frac{3 n}{2 n+1}
$$

\subsubsection{Formulation for Framed Structures: "Formulazione per} Strutture Intelaiate". The third formulation proposed in the Commentary [38] is the so-called "formulazione per strutture intelaiate," which stands for formulation for framed structures $[25,26]$. This method is herein acronymised as FF and is much simpler than the other two described above. Such a simplification is, somehow, partly justified by the fact that more stringent hypotheses and other basic assumptions are met. Its application, however, is limited only to cases of regular frame structures, so that it is reasonable to assume a trend of structural accelerations increasing linearly with the building height. In these limited cases, the maximum acceleration $S_{a}\left(T_{a}\right)$ can be estimated using the following equation:

$$
S_{a}\left(T_{a}\right)= \begin{cases}\alpha S\left(1+\frac{z}{H}\right)\left[\frac{a_{P}}{1+\left(a_{P}-1\right)\left(1-\left(T_{a} / a T_{1}\right)\right)^{2}}\right] \geq \alpha S, & \text { for } T_{a}<a T_{1}, \\ \alpha S\left(1+\frac{z}{H}\right) a_{P}, & \text { for } a T_{1} \leq T_{a}<b T_{1}, \\ \alpha S\left(1+\frac{z}{H}\right)\left[\frac{a_{P}}{1+\left(a_{P}-1\right)\left(1-\left(T_{a} / b T_{1}\right)\right)^{2}}\right] \geq \alpha S, & \text { for } T_{a} \geq b T_{1}\end{cases}
$$

where $\alpha$ is the ratio between the maximum peak ground acceleration $a_{\mathrm{g}}$ on soil type $\mathrm{A}$ at the limit state under consideration and the acceleration of gravity $g$; $S$ is the coefficient that takes into account soil category and topographical conditions; $T_{a}$ is the period of the NSE; $T_{1}$ is the fundamental period of the primary structure in the direction of interest; $z$ is the height of the centre of gravity of the NSE; $H$ is the height of primary structure measured from the foundation level; and $a, b$ and $a_{p}$ are parameters defined in Table C7.2.II of the Commentary [38], all of which are given as a function of $T_{1}$.

To complement the above, it has to be pointed out that $z$ must be measured from the foundation level and that $z=0$ must be assumed for structures with seismic isolation.

Unlike the two previous methods, namely, GF and SF, this one does not require any knowledge of structural modal parameters, exception made for the first period of vibration. An important implication, thus, is the possibility to undertake no structural modelling, neither an accurate/detailed nor a simplified one, as $T_{1}$ could be simply gathered from code-compliant expressions or others available in the literature. On the other hand, it is not possible to include contributions associated with modes higher than the first one, which is considered the only significant one within the FF methodology.

The expressions reported in (5) lay evident that, in this case, the AFRS does not depend on any source of dissipation capacity of the primary structure. In fact, the only parameter affected by the proper choice of reference limit state is the acceleration $\alpha$; as such, any plasticisation of the primary structure, which could take place at the life safety limit state, for instance, do not produce a reduction in the AFRS.

Another aspect that singles out this formulation, in comparison with the previous two, is that neither the spectral shape nor the maximum amplification changes in a continuous fashion with changing the period of vibration of the primary structure. It turns out that AFRS are substantially different for very similar structures that have their natural period ranging between 0.5 and $1.0 \mathrm{~s}$. This happens because the Commentary [38] defines the three parameters 
$a, b, a_{P}$ as a function of the fundamental structural period, assigning them a stepwise trend. Furthermore, the Commentary [38] does not even specify material and/or construction technology for framed structures to which this formulation refers. However, it is very unlikely that cast-inplace reinforced concrete structures, reinforced precast concrete frames, or even steel frames all have structural response/behaviour that results in the exact same values of AFRS. Interested readers are kindly referred to Petrone et al. [26], where the development of this formulation, intended for RC frames, is presented. In the NTC Commentary [38], it is recommended its use for frames, in general, implying that the building period is considered to account for the building material. The mentioned formulation was derived considering building responses associated with a damage limitation state, which can be considered to be relatively well correlated with building period. The influence of material response is expected to be more significant in the case of heavily plastic behaviour, which is not consistent with the assessment of seismic demand on NSEs. It is envisaged that further studies investigate these aspects, checking whether the formulation works well for different material frames.

\section{Case Study}

An example meant to showcase what has previously been described is presented in this section, which provides the calculation of AFRS, both based on NLTHAs and by using the three different simplified formulations provided by the Commentary [38]. The results are compared and discussed highlighting the pros and cons of the simplified formulations.

4.1. Case-Study Structure. For NSEs, the NTC18 [20] recommends compliance with the stability requirement for the SLV. Therefore, a decision was taken to limit the scope and focus of the investigation to this case only, implying thus that the considered return period is chosen accordingly. Considering a building with design life of 50 years, the SLV requires designers/analysts to consider an action (and, hence, a target spectrum) with a probability of exceedance of $10 \%$ in 50 years, which corresponds to a return period of 475 years (see Table 3.2.I of NTC18 [20] and \$C3.2.1 of the Commentary [38]). The case-study structure is supposed to be located near the city of Cassino (Italy) that is characterised by a design peak ground acceleration (PGA) of $0.21 \mathrm{~g}$ for a return period of 475 years.

The analysed building is a simple masonry-infilled RC frame structure extracted from the building portfolio randomly generated in Perrone et al. [7]. The building, a fivestorey, three-bay plane frame representative of the European context, was meant to resemble characteristics of a newly built frame system designed for gravity loads and earthquake resistance in Italy. Both geometry and mechanical properties of the case-study structure were selected accordingly, result from a complete Monte Carlo simulation process in conjunction with a simulated design procedure, and, hence, adhere well with building features frequently found in the Italian built environment.
More specifically, the frame was designed according to Eurocode 8 [39] seismic design provisions assuming design be undertaken in medium ductility class, which means that the so-called ductility class B was considered. As can be inferred from Figure 5, which presents a schematic of the side view, the analysed five-storey three-bay plane frame has an interstorey height of $2.75 \mathrm{~m}$ equal for all floor levels and the bay length (centre-to-centre column spacing in the longitudinal direction) is equal to $4.5 \mathrm{~m}$ for all three bays.

Assuming the studied frame is part of a regular threedimensional structure composed of parallel planar frames with columns spanning $5 \mathrm{~m}$ in the transverse direction (i.e., bay length in building transverse direction), the gravity loads applied to the beams of the frame in question are the following:

Self-weight of the floor slabs, $G_{1}$, equal to $14.63 \mathrm{kN} / \mathrm{m}$ Dead loads of non-structural components/items, $G_{2}$, equal to $6.21 \mathrm{kN} / \mathrm{m}$ and $4.76 \mathrm{kN} / \mathrm{m}$ for floor $1-4$ and the roof, respectively

Live loads equal to $10.13 \mathrm{kN} / \mathrm{m}$

It is pointless to note that the above calculations rely upon the assumption that one-way slabs are considered, as frequently found in Italy and Europe for this structural typology. Table 1 gives the mass values associated with each floor level.

To retrieve the mass values presented in Table 1 , it is worthwhile to mention that the considered RC frame is supposed to be masonry infilled by infill panels having specific weight as reported in Cavaleri and Di Trapani [40]. With regard to their mechanical properties, the vertical and horizontal Young's moduli were taken equal to $6401 \mathrm{MPa}$ and $5038 \mathrm{MPa}$, respectively, whilst the compressive and shear strength values were taken equal to $8.66 \mathrm{MPa}$ and $1.07 \mathrm{MPa}$, respectively. As clarified further in what follows, the infill panels were explicitly considered in the modelling and analysis, in terms of not only weight and corresponding mass but also stiffness and strength. Lastly, it is also worth specifying that the characteristic yielding rebar strength was $375 \mathrm{MPa}$, whilst the unconfined concrete compressive stress was $39 \mathrm{MPa}$.

4.2. Numerical Modelling and Analyses. A detailed planar FE model of the considered frame was developed to carry out both eigenvalue analysis and NLTHA by means of the opensource software OpenSees [41]. A distributed-plasticity approach was adopted to undertake nonlinear dynamic analysis, thus simulating the spreading of inelasticity over the structural member length and cross section. The uniaxial, uniform confinement model proposed by Chang and Mander [42] was considered to simulate the cyclic behaviour of concrete under dynamic loads, whilst a simple bilinear constitutive material model with isotropic strain hardening, namely, uniaxial material Steel01 implemented in OpenSees [41], was assigned to the longitudinal steel rebars. It is noted that except for the masonry infills, the interaction between structural and nonstructural elements was neglected, which in turn means that the NSEs are supposed not to affect the 


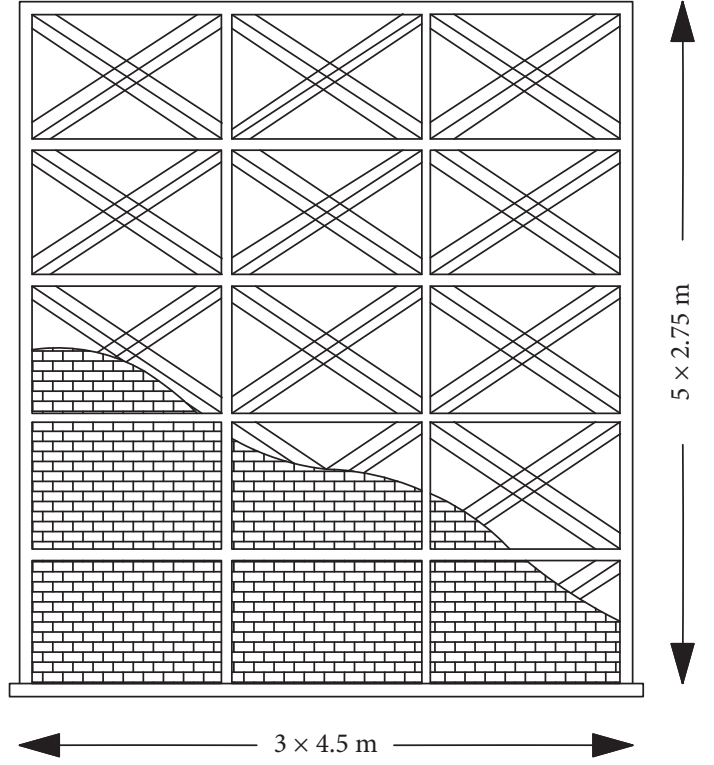

Figure 5: Side view of the case-study building (adapted from Perrone et al. [7]).

TABLE 1: Floor masses.

\begin{tabular}{lc}
\hline Floor level & Mass $(\mathrm{t})$ \\
\hline 1 & 43.7 \\
2 & 43.6 \\
3 & 43.6 \\
4 & 43.6 \\
5 & 42.2 \\
\hline
\end{tabular}

dynamic behaviour of the studied structure in terms of both stiffness and strength.

Each masonry infill wall panel was modelled by an equivalent triple-truss model (see Figure 5). The global stiffness of the panel was distributed amongst three parallel diagonal truss elements by assigning a rate of stiffness and strength equal to $50 \%$ to the central truss and equal to $25 \%$ to each of the off-diagonal trusses. The Rayleigh tangent stiffness proportional viscous damping was introduced in the numerical model with $5 \%$ of critical damping specified in the first two elastic modes of vibration. For more specific details on the implemented numerical modelling approach, interested readers are directly referred to Perrone et al. [7]. The same consideration can be made for what concerns the suite of 20 earthquake ground motion taken, from the PEER NGA-West database [43], as input for NLTHAs. In particular, hazard-consistent record selection was undertaken based on spectral compatibility with a conditional mean spectrum according to the methodology proposed by Jayaram et al. [44] for the city of Cassino, in Italy. The latter was chosen to represent a medium-to-high seismicity in Italy.

NLTHAs were carried out alongside eigenvalue analysis, and Table 2 summarises natural period $T$, mode shape $\phi$, and transformation factor $\Gamma$ for the first three modes of the casestudy masonry-infilled RC planar frame.
TABLE 2: Eigenvalue analysis results.

\begin{tabular}{lccc}
\hline & Mode 1 & Mode 2 & Mode 3 \\
\hline T (s) & 0.45 & 0.15 & 0.09 \\
$\phi_{1}$ & 0.22 & -0.70 & 1.25 \\
$\phi_{2}$ & 0.50 & -1.08 & 0.62 \\
$\phi_{3}$ & 0.73 & -0.67 & -1.10 \\
$\phi_{4}$ & 0.90 & 0.24 & -0.84 \\
$\phi_{5}$ & 1.00 & 1.00 & 1.00 \\
$\Gamma$ & 1.27 & -0.409 & 0.19 \\
\hline
\end{tabular}

For the sake of clarity and completeness, it has to be pointed out that the transformation factors $\Gamma_{i}$ can be calculated as reported in

$$
\Gamma_{i}=\frac{\phi_{i}^{T} M \tau}{\phi_{i}^{T} M \phi_{i}},
$$

where $\tau$ is a transformation vector corresponding to the considered seismic direction, $\phi_{i}$ is the ith mode shape, normalised to its maximum, and $M$ is the mass matrix consisting of the values given in Table 1 .

The above being stated, NLTHA allowed calculation of the time history acceleration response of each floor for each of the 20 ground motions considered as seismic input. As schematically shown by Figure 6, these acceleration time histories are the seismic input to which the NSEs are subjected and starting from these acceleration records, it is possible to calculate the AFRS.

4.3. AFRS and Comparisons. As previously mentioned, NLTHAs were performed to obtain the floor acceleration time histories, leading in turn to the calculation of the AFRS for each floor of the building structure. For the case study treated here, the AFRS were calculated only at the top floor because of the regularity in plan and elevation that characterises the case-study structure. Due to this, in fact, the AFRS with higher spectral ordinates along the building height are indeed expected at the roof. Figure 7 shows the 20 individual AFRS obtained from NLTHAs of the structure with each ground motion considered, together with the median acceleration floor response spectrum (MAFRS) for a return period of 475 years, the latter corresponding to SLV or life safety limit state.

The first thing to note is that all these spectral shapes feature the same increasing trend till the acceleration peak is attained around the fundamental period of the structure. It is also possible to note that, albeit much less pronounced, a second peak occurs around the vibration period of the second mode, that is, about $0.15 \mathrm{~s}$. In this case, however, the peak/amplification is not very significant, owing to the regularity of the structure, which implies that a large part of the effective modal mass is coupled with the first mode of vibration. This peak would certainly be much more pronounced (i) for irregular or highly irregular structures or (ii) when, moving along the building height, the floor level is taken where the modal displacement associated with the second mode is maximum. Although from a structural point of view an effect like this might be considered as a secondary 


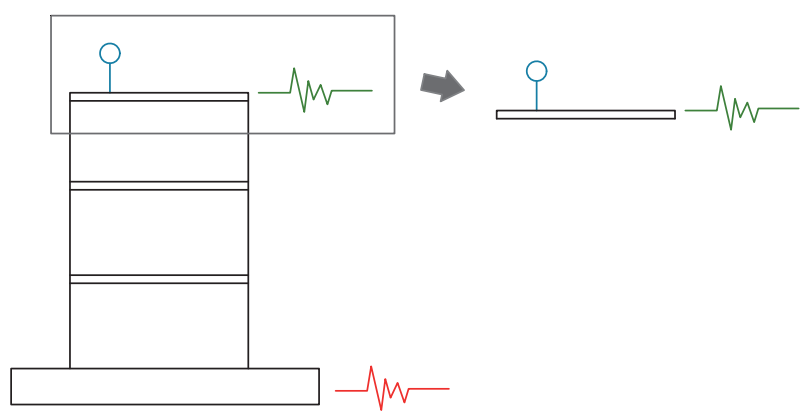

Figure 6: Ground and floor motions.

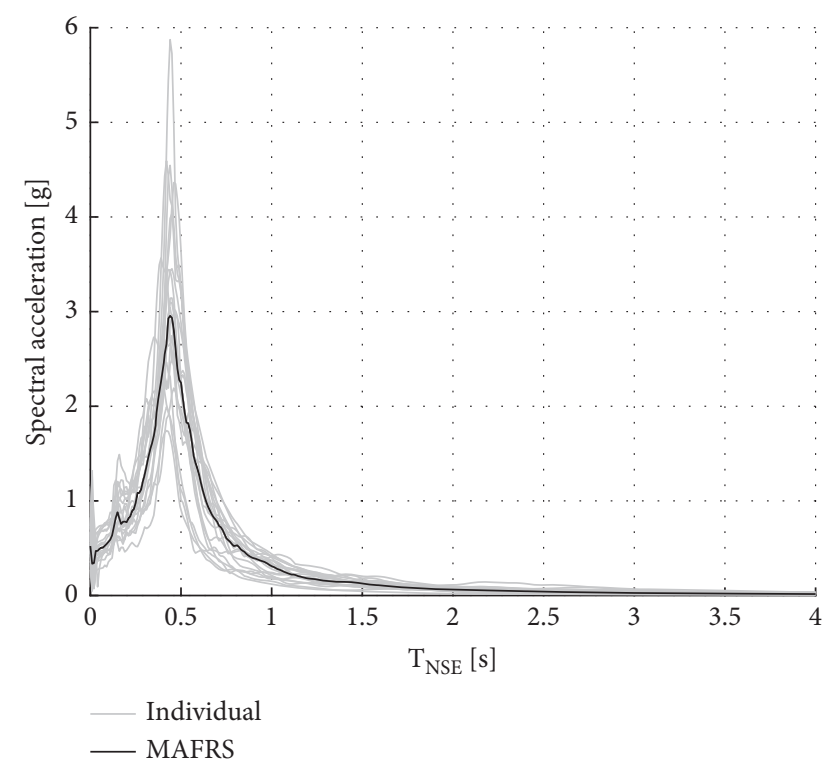

Figure 7: AFRS obtained by means of NLTHAs.

effect of no particular relevance, the effect on NSEs could be nonnegligible or even important. Some NSEs, such as for instance electrical cabinets or air treatment machineries, may be characterised by natural periods ranging between $0.15 \mathrm{~s}$ and $0.50 \mathrm{~s}$, whose range may match the higher modes of this and other similar structures. Such a matter must be duly accounted for and evaluated on a case-by-case basis. As an example meant to showcase the above, Figure 8 presents a comparison with an irregular counterpart frame, where the rightmost and leftmost top two storeys of the case-study planar frame are no longer present, thus demonstrating a much more pronounced amplification peak (around the second mode of the structure).

Figure 9 presents individual AFRS from NLTHAs along with MAFRS, the latter being taken as a reference for comparison with spectra from simplified/analytical formulations codified in the NTC18 [20] and MAFRS plus one standard deviation. Code-compliant simplified AFRS estimates are presented alongside and follow the nomenclature introduced hereinafter:

NTC18_GF is the median acceleration floor response spectrum obtained from the GF formulation (or

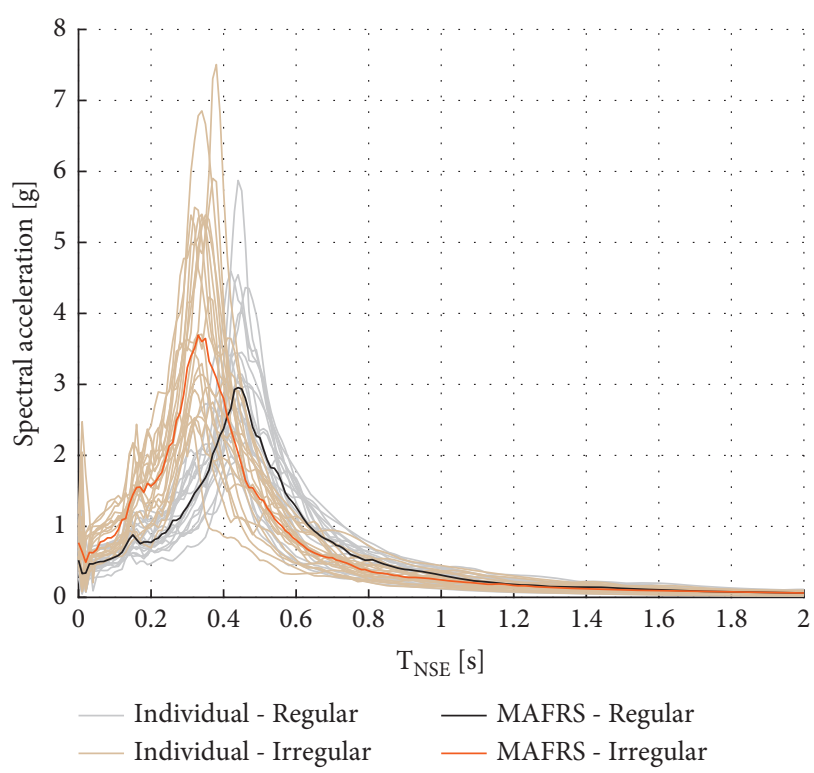

FIGURE 8: NLTHA-driven AFRS and comparison with those for an irregular structure counterpart.

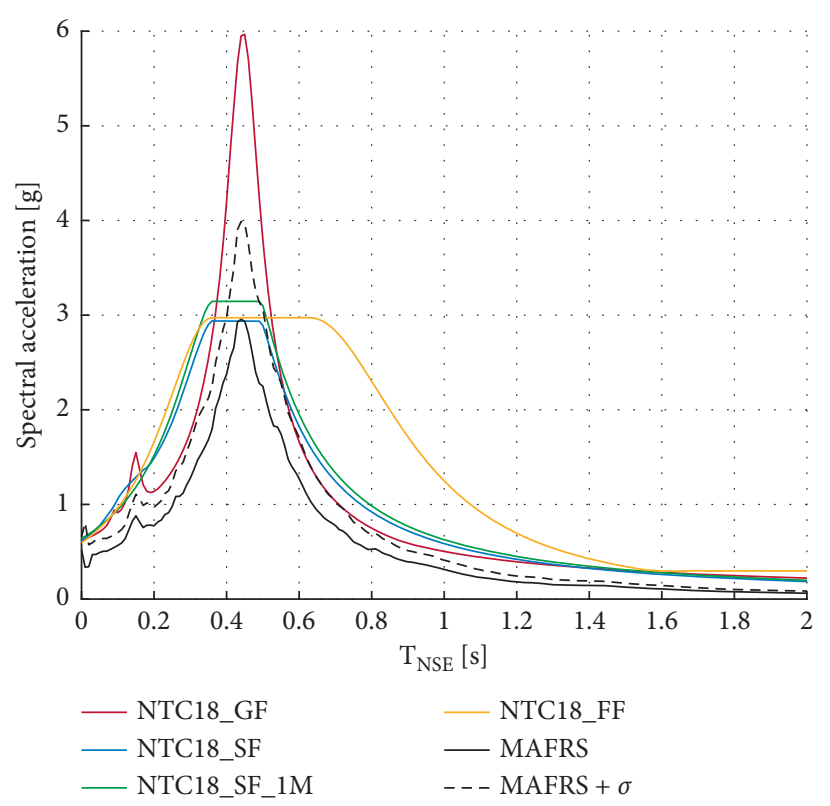

FIgURE 9: Comparison between NLTHA-driven AFRS and analytical code-compliant counterparts.

general formulation) provided by the NTC18 Commentary [38];

NTC18_SF is the median acceleration floor response spectrum obtained from the SF formulation (or simplified formulation) provided by the NTC18 Commentary [38]; NTC18_SF_1M coincides with NTC18_SF exception made for the fact that calculation was undertaken considering only the fundamental structural period; NTC18_FF is the median acceleration floor response spectrum obtained from the FF 
formulation (or formulation for framed structures) provided by the NTC18 Commentary [38].

For completeness, it is worth stating explicitly that the acronym MAFRS identifies the reference floor spectrum derived as the median of the 20 NLTHA-driven floor spectra, whereas MAFRS $+\sigma$ coincides with MAFRS except that one standard deviation $(\sigma)$ is added. Additionally, it is noted that regardless of the considered analytical formulation, median spectral accelerations are given in Figure 9 for each of them because each NTC18-conforming calculation procedure is repeated 20 times, one per each earthquake ground motion. In other words, median is taken over the set of ground motions for each analytical calculation procedure, assuming seismicity coefficients in line with those considered in Perrone et al. [7]. It is also worthwhile to add that $\xi_{a}$ was set to $5 \%$ and that the $\beta$ coefficient in NTC18_GF was conservatively taken equal to 0.5 .

To start making a critical review of results showcased by Figure 9, NTC18_GF and its trend are first considered. For the analysed return period, this code-conforming formulation overestimates significantly the reference NLTHAdriven floor spectrum, MAFRS, so much so that it can only approximate the maximum spectrum obtained from the set of 20 NLTHAs carried out. Such a high overestimation of floor spectral ordinates is certainly ascribed to the nonlinear behaviour that the structure experiences at the SLV.

Furthermore, for completeness, it should be pointed out that the general formulation proposed in the NTC18 Commentary [38] suggests evaluating the floor spectrum based on the elastic or overdamped ground acceleration spectrum, without indicating, however, how to calculate the overdamping-related reduction coefficient. At the SLV, the accelerations are usually high enough to activate the nonlinear behaviour of the primary structure, thus entailing that part of the seismic energy is dissipated by the structural hysteretic response and, hence, is not transferred to its floors. However, when adopting an elastic spectrum reduction coefficient of the elastic spectrum calculated as a function of the structural/design behaviour factor, the obtained floor spectrum is clearly underestimated, as can be inferred from Figure 10. This happens because at the SLV, the primary structure does not develop all the plasticity for which it was designed, the latter being instead mobilised at the CLS. As such, it is laid bare that assuming a structural behaviour factor equal to the design one would result in an excessive reduction of the earthquake-induced actions. It can thus be inferred that even if GF does not lead to results that are excessively inaccurate, its simplicity, or a vast part of it, is lost when the primary structure is expected or supposed to enter the inelastic/plastic range of its response. In this case, nonlinear analyses are required to estimate the actual ductility developed by the structure ( $\mu=2$ in this case) and, hence, the correct reduction factor of the elastic ground spectrum. These operations may be carried out, for example, by adopting the provisions of the N2 method [45], as also proposed by Eurocode 8 [39]. Note that the structural behaviour factor used to make the first attempt in Figure 10 was calculated considering a ductility class medium

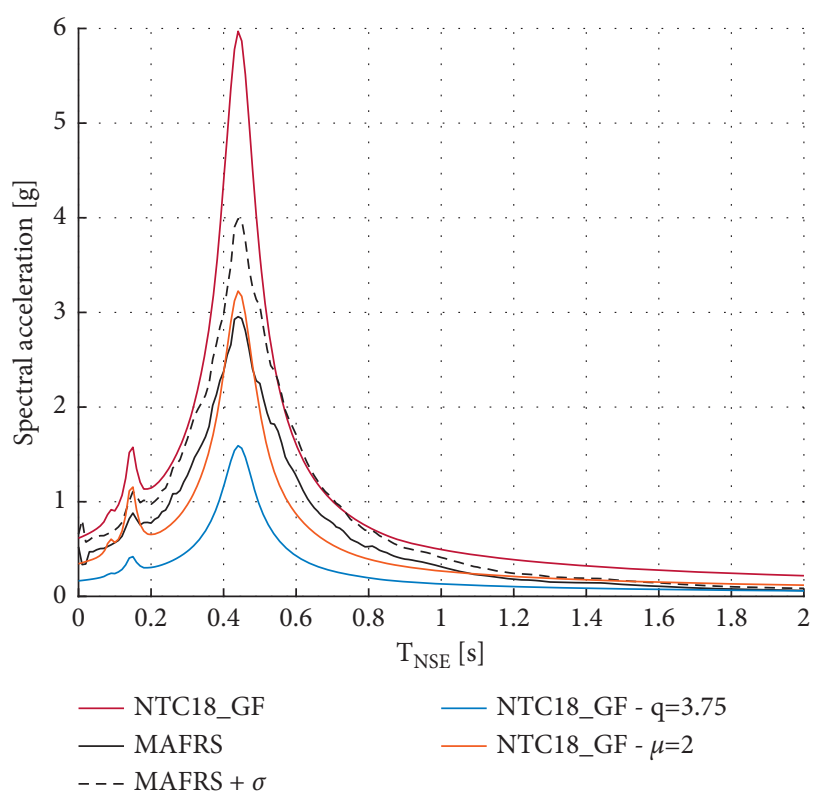

FIGURE 10: Comparison between NTC18_GF and overdamped NTC18_GF.

according to Eurocode 8 [39] and assuming the $\alpha_{u} / \alpha_{1}$ ratio equal to 1.25 , where $\alpha_{u}$ is the value by which the horizontal seismic action is multiplied in order to form plastic hinges in a number of sections sufficient for the development of overall structural instability, while $\alpha_{1}$ is the value by which the horizontal seismic action is multiplied in order to first reach the flexural resistance in any member in the structure [39].

Moving on then with SF (or, in other words, the simplified formulation of the Commentary [38]), it can be gathered, from the curves shown in Figure 9, that the floor spectrum was calculated by means of two different ways, as permitted by the NTC18 Commentary [38]. As very briefly mentioned above, and more clearly stated here, the latter ways are referred to as

NTC18_SF, which is the spectrum obtained by combining the first three vibration modes of the structure; NTC18_SF_1M, which is the spectrum obtained when simplifying further the calculation procedure. More in detail, when masses are uniformly distributed along the height, this formulation expects analysts to be able/ allowed to calculate the spectrum by considering only the first vibration mode of the building and by obtaining the modal participation coefficient as a function of the $n$ number of floors, according to

$$
\Gamma_{1}=\frac{3 n}{2 n+1}=\frac{3 \cdot 5}{2 \cdot 5+1}=1.36 .
$$

The comparison between these two spectra, those tagged as NTC18_SF and NTC18_SF_1M, renders clear that (i) the spectral acceleration at the plateau is, somehow expectedly, influenced mainly by the fundamental mode, and that (ii) 
the higher modes contribute less to the maximum spectral accelerations, this latter consideration being valid only when the first and higher modes are well separated (as for the present case-study frame). In addition, it is worth mentioning that estimating the modal participation coefficient as a function of the number of floors produces conservative results, no matter how approximate such an assumption is. Indeed, it implies safe results for design, leading to the calculation of higher spectral accelerations. Finally, it can be concluded that although the contribution of higher modes to spectral acceleration peak is rather limited, they significantly modify accelerations around their vibration period. These acceleration values are not very high for this case-study structure, but much greater impacts would be expected, if irregular buildings with a significant portion of the participating mass associated with higher modes were to be considered.

The third formulation proposed in the NTC18 Commentary [38], whose application is limited to regular framed structures, is a good fit in this case. The high level of simplification associated with such an approach does not turn into huge limitations, when it comes to compare the obtained spectrum with the NLTHA-driven one taken as reference, namely, MAFRS, as well as with the others coming from analytical, code-compliant formulations. This formulation correctly evaluates the spectral acceleration peak corresponding to around the first structural period, with the plateau and the MAFRS peak value that are nearly coincident, but it certainly overestimates, in this case at least, the nonstructural period range over which the spectral accelerations are distributed (in other words, where spectral amplifications are supposed to take place). As far as this latter aspect is concerned, it should, however, be noted that having a wider plateau is conservative in terms of spectral accelerations. The positive aspect in this sense is that this simple formulation provides safe acceleration estimates for a period range that could characterise most of NSEs installed in a building, although spectral accelerations more than doubled are sometimes produced both for short-period NSEs and for long-period ones. It is clear that, however, the extent of this conservatism depends on the value of the first vibration period of the primary structure.

To close the treatment, it is worth adding that the NTC18_FF approach, together with the related simplifications, is somehow comparable with those adopted by other international codes, such as Eurocode 8 [39] and ASCE07-16 [46]. The former results only in a poor approximation of median top floor spectral accelerations, regardless of the considered nonstructural period, whilst the latter leads to a narrower plateau and a more accurate prediction of spectral acceleration for periods around the second mode of the structure, as can be seen from Figure 11.

4.4. Seismically Qualified NSEs. By following the indications provided in standards specific for the seismic qualification of NSEs (e.g., [31]), it is possible to pursue such an objective for many of the most common NSEs that are part of the socalled building system, the latter being intended as the

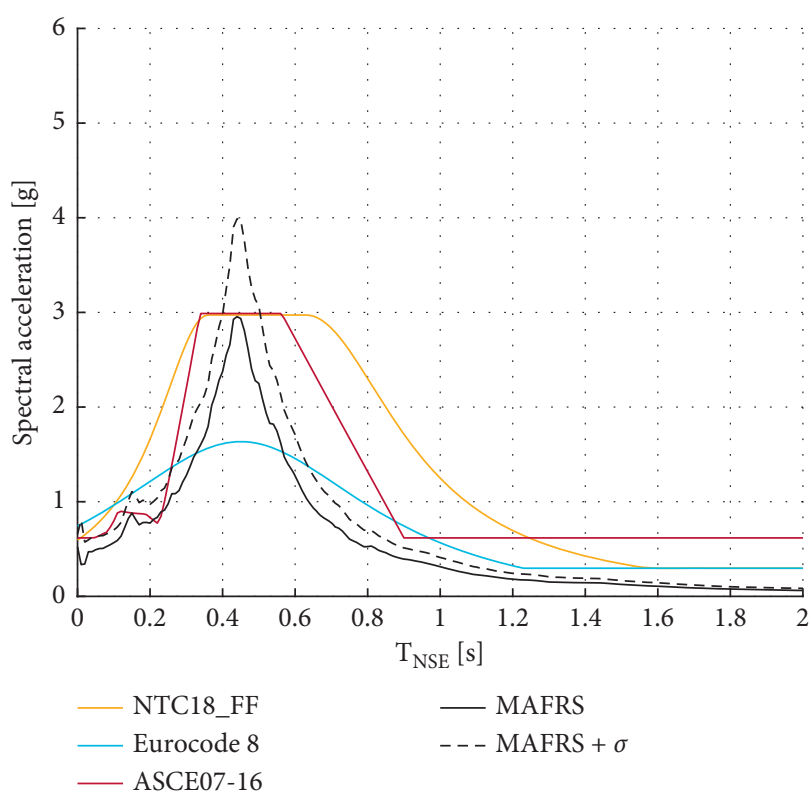

FIGURE 11: Comparison with Eurocode 8 [39] and ASCE07-16 [46].

ensemble of NSEs and building skeletal frame conceived as a whole system. Thus, the seismic qualification, should it be experimental, numerical, or mixed, is a means to carrying out stability (and possibly functionality) verifications for a predetermined level of earthquake-induced actions on the NSE of interest. When planning and designing the installation of a qualified NSE, the designer must only choose one element that is qualified for a level of seismic input (calculated according to what previously shown/discussed) that is higher than that expected at the installation point. What needed, thus, is to simply compare spectra and verify that the spectrum used for the qualification-RRS in the case of an experimental one-envelopes the case-specific spectrum. The envelope may be extended to either the entire frequency range considered in the qualification or at least around the natural frequencies of the NSE considered.

As an example, Figure 12 shows a comparison between the acceleration floor spectrum for the case-study structure analysed herein (i.e., MAFRS is taken in this case) and a would-be generic "Qualification Spectrum." Both Figures 10(a) and 10(b) show the exact same comparison from a different perspective: the spectral acceleration is shown in Figure 10(a) as a function of the period of the NSE (as common in civil engineering applications), whilst the same curves are shown in Figure 10(b) as a function of the NSE frequency or nonstructural frequency. Note that, in this case, the horizontal axis is reported on a logarithmic scale, as done more than often for some types of NSEs and plant equipment.

When referring to Figure 12, a generic NSE, qualified for the "Qualification Spectrum" shown therein, is suitable for installation at the top floor of the case-study structure, once verified that its own natural frequency is sufficiently shifted away from that of the primary structure where the NSE is to be installed. Purely indicatively, the qualification could be taken as passed or accepted, with respect to the case-specific 


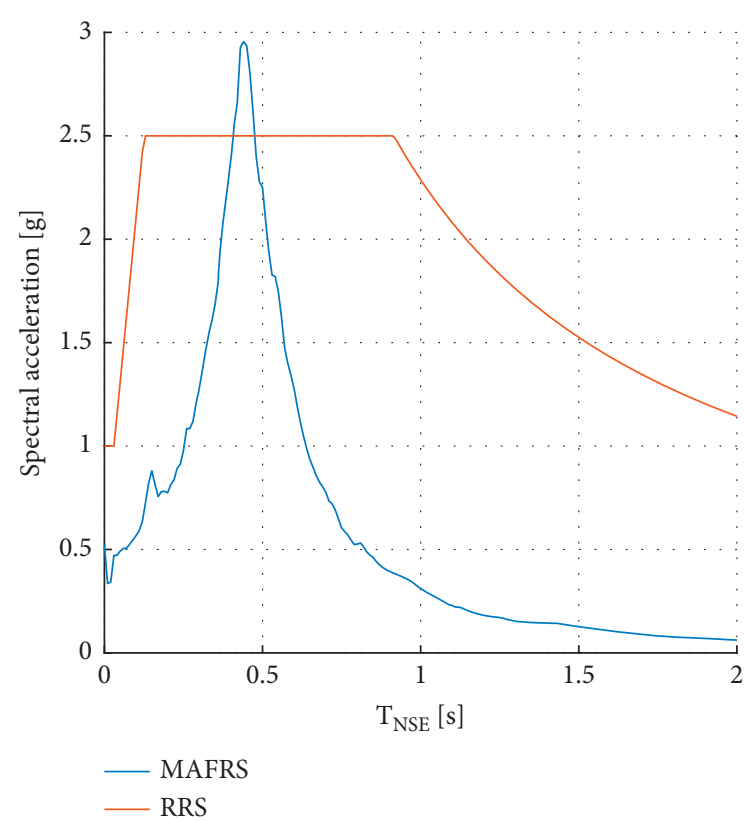

(a)

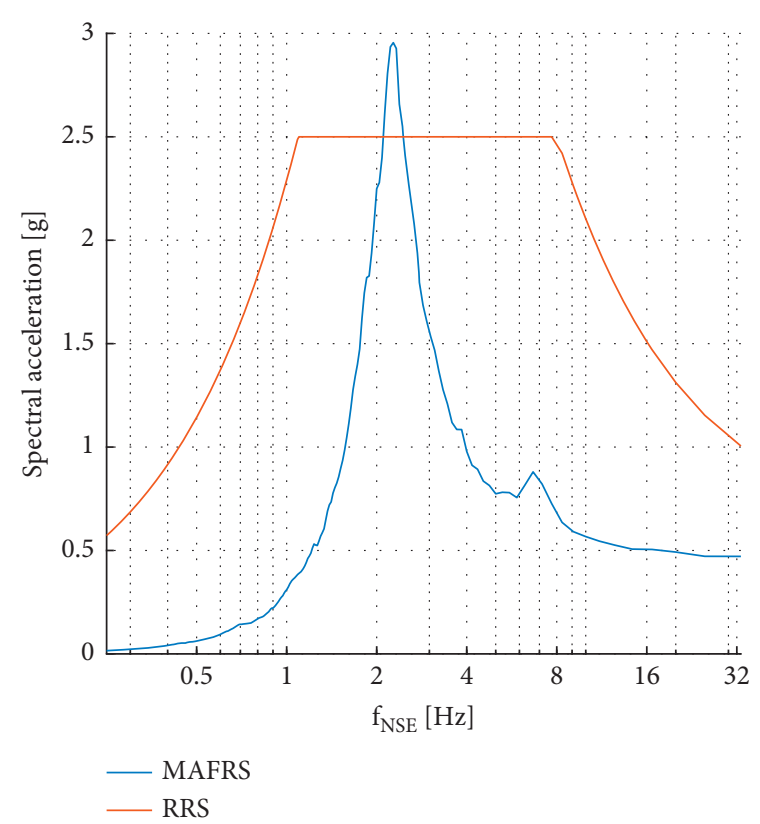

(b)

Figure 12: Comparison between MAFRS and "Qualification Spectrum": (a) acceleration-period and (b) acceleration-frequency curves.

floor spectrum, once the frequency of the NSE is checked to be between $1 \mathrm{~Hz}$ and $1.7 \mathrm{~Hz}$ or higher than $3 \mathrm{~Hz}$.

To ensure proper design and installation, the manufacturer of the NSE shall provide an indication of the spectrum to be used for the seismic qualification (possibly described by standard levels of the reference regulation/ standard chosen for the qualification) and shall specify vibration periods (or frequencies) of the manufactured NSE. The structural engineer/engineering team in charge of building design shall provide the acceleration spectrum at the installation point. The electrical or mechanical or plant engineer shall then select the correct NSE to install out of those listed in a likely manufacturer's catalogue. Certainly, it is equally important to respect all of the installation conditions indicated by the manufacturer, the latter being fully compliant with those assumed for the seismic qualification. Indeed, the correct behaviour of any NSE in a building cannot separate from proper connection or anchoring to the primary structure whichever this be.

Furthermore, it is certainly worth stating explicitly that when dealing with SLV and locations with high seismicity (or high seismic hazard), floor spectra are very likely to reach high or very high acceleration values. In such cases, carrying out the seismic qualification through experimental tests could not be taken for granted, as the spectrum required for the testing could exceed the performance of available shaking tables or of a vast part. For situations like this, it may be deemed appropriate (i) to make use of seismic qualification testing to get experimental evidence of performance achievable for earthquake-induced actions lower than required and then (ii) to make use of the obtained experimental data to develop/calibrate a numerical model, thereby extending the qualification to the desired level of seismic input.
4.5. Design of Nonqualified NSEs. Unfortunately (from a product standardisation point of view), albeit not unexpectedly, not all of NSEs could be subjected to seismic qualification beforehand; indeed, in many instances, the NSE or equipment is part of a more or much more complex system that is to be designed, on a case-by-case basis, based on the specific installation context and/or process. For example, if suspended distribution systems (e.g., sprinkler networks, ventilation systems) inside a building are taken as a reference, their seismic response is strongly affected by the layout inside the primary structure and by the geometry of the system itself, which must adapt to the individual application, although all of these systems are composed of standard elements assembled together to replicate or form key items that make the system as a whole.

In such cases, the design issue cannot be solved through a pure or mere process of comparison, between two spectra, but rather other means should necessarily be introduced to face the problem. For instance, it may be feasible/envisaged to qualify single standard components (i.e., archetypes repeated in series or in parallel to form the nonstructural system in question), with the latter being assembled/installed/arranged according to appropriate sets of rules determined experimentally or numerically or both by the manufacturer/producer. The rules to define the layout of the individual components must be determined considering the interaction amongst basic/key elements, for instance, ensuring that each will not be assigned excessive masses/loads. Alternatively, the cyclic response of basic components, as well as their eventual interaction, could firstly be characterised experimentally by quasistatic cyclic tests in such a way that simplified numerical models could then be developed. The latter models, fed with experimental data, could in turn be used for the modelling and analysis of an entire 
NSE system/layout by subjecting it to acceleration records compatible with the floor spectrum corresponding to each specific installation.

Unless there are mutual interactions amongst the basic components of a nonstructural system or layout, each of them is subjected to a seismic force that equals the product of the mass (of the single NSE) and the spectral acceleration. The latter must be taken as the spectral ordinate corresponding to the period of the component or single NSE (which is not necessarily easy-to-estimate). In accordance with code indications (and actual mechanical/physical behaviour), the so-calculated seismic force can thus be reduced through a behaviour factor, which is function of the ductility of the NSE (and which needs careful calibration). The force acting on the NSE to be designed should then be used both for stability and resistance verification checks of its own supporting structure and for the sizing of the anchoring system to the primary structure.

\section{Conclusions}

The fundamental role played by nonstructural elements (NSEs) in terms of safety for building occupants and preservation of building functionality is now unanimously recognised. Within this context, national and international standards are currently adapting and start providing designers, manufacturers, and installers with the necessary tools and means to ensure adequate seismic behaviour of nonstructural components installed in a building. In Italy, the main reference for construction is the so-called "Decreto Ministeriale 17 gennaio 2018, "Norme Tecniche per le Costruzioni" [20]," which defines, for NSEs also, both minimum performance targets as well as the roles and responsibilities of all actors involved in the design-productioninstallation chain. With this in mind, obviously, the fulfilment of all mandatory requirement cannot take place without a correct evaluation of both seismic input and NSE performance.

For most NSEs, the input shall be specified by means of appropriate floor spectra. As shown before, these can be calculated rigorously by accurate dynamic analyses, possibly other than linear, or by simplified methods of proven validity, as also stated in the Italian building code NTC18 [20]. The Commentary of the Italian Building Code "Circolare Applicativa NTC18” [38], which accompanies prescriptive rules, suggests three simplified formulations that have been summarised first and then applied to the analysed case-study structure, namely, a five-storey, three-bay masonry-infilled RC planar frame designed for medium ductility class according to European rules [39]. The level of simplification involved in the three formulations is proportional to the number of assumptions underlying each one. Nevertheless, it becomes crystal-clear that much of calculation simplicity is lost as soon as the nonlinear behaviour of the primary, supporting structure comes into play. On the other hand, it should be acknowledged that the proposed formulations minimise, significantly, the calculation effort when compared with methods that make use of nonlinear analyses; in any case, however, a reliable and possibly accurate structural model is still necessary to understand the dynamic behaviour of the primary structure. Not surprisingly either, an analytical method that might solve the problem of acceleration floor response spectrum (AFRS) with no account of modal parameters of the primary structure is difficult to imagine, as the latter (i.e., modal parameters) drive the structural response affecting the propagation of seismic excitation throughout the building, from its foundations all along the height. Out of the three investigated formulations proposed in the Italian building code [20], the last-listed, namely, "formulation for framed structures" is the one and only that purely considers just the first natural period of the structure. With this formulation, however, the presented results and comparisons did showcase an accurate prediction of the AFRS peak with a wider plateau nonetheless, as the method in question provides not more than a conservative approximation of likely demand on NSEs, for a relatively wide range of both short- and long-period ones. It should also be noted that, counterintuitively, the level of conservativism associated with the formulations proposed by the Commentary [38] does not increase with the level of simplification granted by each of them. More specifically, and somewhat surprisingly, the most complex method, namely, general formulation, provides spectral accelerations that are overly conservative (despite an accurate prediction of overall spectral shape), whilst the two simplest methods (i.e., simplified formulation and formulation for framed structures) lead to the calculation of a similar AFRS peak, which is also more aligned with that produced by accurate nonlinear time history analyses.

Inaccurate estimate of AFRS could jeopardise the safety of design, as the latter are the most credible input any design should be targeted to. On the one hand, the underestimation of seismic actions on a NSE leads to a cost reduction that is only merely fictitious, and certainly not to a reduction of overall costs, should direct and indirect loss-related issues be obviously involved. On the other hand, it is worth stating that in order to seek and ensure the most proper balance between safety and costs, the only rationale way forward is to standardise products before they reach the market. Indeed, the main purpose of any standardisation process has ever been to ensure consistency and uniformity in quality and performance over a production chain, making it easier for manufacturers and designers to produce and supply products in line with customers' requirements and needs. For instance, such a concept was first applied by the Bell Laboratories, which already back in the 1970s developed the first set of requirements, seismic ones included, for the equipment that were to become part of the US telecommunication network. The concepts of product standardisation well fit the case of NSEs, often produced on a large-scale basis, and these concepts and principles are, nowadays, adapting and spreading to each type of these products through the release of dedicated standards. This approach is also well suited to the objective of ensuring adequate seismic performance of NSEs: product standards that explicitly consider the problem of seismic resistance are becoming increasingly common. When working with NSEs produced in series, the best approach to guarantee the correct performance is to pursue a 
seismic qualification, which can be either an experimental or numerical or mixed one. In Italy, for instance, there is a growing demand for NSEs, classified as "antiseismic" ones, and companies are moving to qualify their products. Until a few years ago, these procedures were only limited to the supplies of particularly critical facilities (i.e., nuclear power plants). In Italy, there is still much work to do towards this direction, considering also that many international standards, currently not binding, are not applied these days except in too rare cases. The attention paid to the role of NSEs will continue to grow in the near future, and so will the commitment of manufacturers towards ensuring adequate seismic performance as a result of market's needs.

Certainly, making roles and responsibilities explicit and clear in the current NTC18 [20] has posed great emphasis on this issue, although it is not a belief that, even before 2018, the legislator's mind/intention was to ensure that performance had covered the entire building system and not just the primary structure itself. In addition to NTC18 [20], another important, albeit implicit, reference applicable in Italy to the field of NSEs is surely the "Decreto Legislativo 81 del 9 Aprile 2008, "Testo Unico sulla salute $e$ sicurezza sul lavoro"' [47], whose clause 64 states that an obligation of the employer is to verify that the emergency exits and paths are clear so that they can be used in case of need. Besides, in Annex IV \$1.1.1, the Decree states that buildings housing workplaces or any other item and structure therein must be stable enough for their type of use and environmental characteristics. Clearly, the availability of emergency exits and the guarantee of stability corresponding to the workplace environment characteristics/ features cannot be separated from an adequate seismic design.

\section{Data Availability}

All data generated or analysed during the study can be made available upon reasonable request to the corresponding author.

\section{Disclosure}

The work presented in this paper has been developed within the activities of the Eucentre-DPC 2019-2021 Research Programme, WP11 "Caratterizzazione della Risposta Sismica di Elementi Nonstrutturali."

\section{Conflicts of Interest}

The authors declare that they have no conflicts of interest.

\section{Acknowledgments}

The authors would like to express their gratitude to the Italian Department of Civil Protection for the financial support received through a three-year framework programme established with the European Centre for Training and Research in Earthquake Engineering.

\section{References}

[1] E. Miranda and S. Taghavi, "Estimation of seismic demands on acceleration-sensitive nonstructural components in critical facilities," in Proceedings of the Seminar on Seismic Design, Performance, and Retrofit of Nonstructural Components in Critical Facilities, pp. 347-360, Applied Technology Council (ATC 29-2), Newport Beach, Newport Beach, CA, USA, October 2003.

[2] S. Taghavi and E. Miranda, "Estimation of seismic acceleration demands in building components," in Proceedings of the 13th World Conference on Earthquake Engineering, Vancouver, Canada, June 2004.

[3] E. Miranda, G. Mosqueda, G. Retamales, and G. Pekcan, "Performance of nonstructural components during the 27 February 2010 Chile earthquake," Earthquake Spectra, vol. 28, no. S1, pp. S453-S471, 2012.

[4] P. M. Calvi, M. Moratti, and A. Filiatrault, "Studio della risposta di elementi non strutturali di edifici scolastici soggetti ad eventi sismici," Progettazione Sismica, vol. 6, 2015 in Italian.

[5] T. Sullivan, P. M. Calvi, and D. Bolognini, "Valutazione degli spettri di piano per la progettazione sismica di elementi non strutturali," Progettazione Sismica, vol. 6, 2015 in Italian.

[6] D. Perrone, P. M. Calvi, R. Nascimbene, E. C. Fischer, and G. Magliulo, "Seismic performance of non-structural elements during the 2016 Central Italy Earthquake," Bulletin of Earthquake Engineering, vol. 17, no. 10, pp. 5655-5677, 2019.

[7] D. Perrone, E. Brunesi, A. Filiatrault, and R. Nascimbene, "Probabilistic estimation of floor response spectra in masonry infilled reinforced concrete building portfolio," Engineering Structures, vol. 202, Article ID 109842, 2020.

[8] N. Achour, M. Miyajima, M. Kitaura, and A. Price, "Earthquake-induced structural and nonstructural damage in hospitals," Earthquake Spectra, vol. 27, no. 3, pp. 617-634, 2011.

[9] A. Baird, A. S. Tasligedik, A. Palermo, and S. Pampanin, "Seismic performance of vertical nonstructural components in the 22 February 2011 Christchurch Earthquake," Earthquake Spectra, vol. 30, no. 1, pp. 401-425, 2014.

[10] L. Di Sarno, G. Magliulo, D. D’Angela, and E. Cosenza, "Experimental assessment of the seismic performance of hospital cabinets using shake table testing," Earthquake Engineering \& Structural Dynamics, vol. 48, no. 1, pp. 103-123, 2019.

[11] A. Masi, G. Santarsiero, M. R. Gallipoli et al., "Performance of the health facilities during the 2012 Emilia (Italy) earthquake and analysis of the Mirandola hospital case study," Bulletin of Earthquake Engineering, vol. 12, no. 5, pp. 2419-2443, 2014.

[12] G. Gabbianelli, D. Perrone, E. Brunesi, and R. Monteiro, "Seismic acceleration and displacement demand profiles of non-structural elements in hospital buildings," Buildings, vol. 10, no. 12, p. 243, 2020.

[13] R. J. Merino Vela, E. Brunesi, and R. Nascimbene, "Derivation of floor acceleration spectra for an industrial liquid tank supporting structure with braced frame systems," Engineering Structures, vol. 171, pp. 105-122, 2018.

[14] R. J. Merino Vela, E. Brunesi, and R. Nascimbene, "Seismic assessment of an industrial frame-tank system: development of fragility functions," Bulletin of Earthquake Engineering, vol. 17, no. 5, pp. 2569-2602, 2019.

[15] R. J. M. Vela, E. Brunesi, and R. Nascimbene, "Floor spectra estimates for an industrial special concentrically braced frame 
structure," Journal of Pressure Vessel Technology-Transactions of the ASME, vol. 141, no. 1, Article ID 010909, 2019.

[16] R. J. Merino, D. Perrone, and A. Filiatrault, "Consistent floor response spectra for performance-based seismic design of nonstructural elements," Earthquake Engineering \& Structural Dynamics, vol. 49, no. 3, pp. 261-284, 2020.

[17] E. Fema, Reducing the Risks of Nonstructural Earthquake Damage: A Practical Guide, ATC, CA, USA, 2011.

[18] DPC-Dipartimento della Protezione Civile Presidenza del Consiglio dei Ministri, "Linee guida per la riduzione della vulnerabilità di elementi non strutturali arredi e impianti," 2009.

[19] UNI EN 81-77, Regole di sicurezza per la costruzione e l'installazione degli ascensori - Applicazioni particolari per ascensori per persone e per merci - Parte 77Ascensori sottoposti ad azioni sismiche", Italian, 2014.

[20] Ministero delle Infrastrutture e dei Trasporti, Decreto 17 gennaio 2018: Aggiornamento delle Norme Tecniche per le CostruzioniG.U., Italian, no. 42, 2018.

[21] S. D. Abbati, S. Cattari, and S. Lagomarsino, "Theoreticallybased and practice-oriented formulations for the floor spectra evaluation," Earthquakes and Structures, vol. 15, no. 5, pp. 565-581, 2018.

[22] H. Anajafi, R. A. Medina, and E. Santini-Bell, "Inelastic floor spectra for designing anchored acceleration-sensitive nonstructural components," Bulletin of Earthquake Engineering, vol. 18, no. 5, pp. 2115-2147, 2020.

[23] P. M. Calvi and T. J. Sullivan, "Estimating floor spectra in multiple degree of freedom systems," Earthquakes and Structures, vol. 7, no. 1, pp. 17-38, 2014.

[24] D. D’Angela, G. Magliulo, and E. Cosenza, "Towards a reliable seismic assessment of rocking components," Engineering Structures, vol. 230, Article ID 111673, 2021.

[25] C. Petrone, G. Magliulo, and G. Manfredi, "Floor response spectra in RC frame structures designed according to Eurocode 8," Bulletin of Earthquake Engineering, vol. 14, no. 3, pp. 747-767, 2016.

[26] C. Petrone, G. Magliulo, and G. Manfredi, "Seismic demand on light acceleration-sensitive nonstructural components in European reinforced concrete buildings," Earthquake Engineering \& Structural Dynamics, vol. 44, no. 8, pp. 1203-1217, 2015.

[27] M. Surana, M. Pisode, Y. Singh, and D. H. Lang, "Effect of URM infills on inelastic floor response of RC frame buildings," Engineering Structures, vol. 175, pp. 861-878, 2018.

[28] D. D’Angela, G. Magliulo, and E. Cosenza, "Seismic damage assessment of unanchored nonstructural components taking into account the building response," Structural Safety, vol. 93, Article ID 102126, 2021.

[29] UNI EN 13964, "Controsoffitti-requisiti e metodi di prova," Italian, 2014.

[30] Federal Emergency Management Agency (Fema), "Interim protocols for determining seismic performance characteristics of structural and nonstructural components through laboratory testing," Report No. FEMA 461, Washington D.C., USA, 2007.

[31] International Code Council Evaluation Service (Icc-Es), AC156 Acceptance Criteria for the Seismic Qualification of Nonstructural Components, Brea, California, USA., 2012.

[32] M. C. Chen, E. Pantoli, X. Wang et al., "Full-scale structural and nonstructural building system performance during earthquakes: Part I-specimen description, test protocol, and structural response," Earthquake Spectra, vol. 32, no. 2, pp. 737-770, 2016.
[33] E. Cosenza, L. Di Sarno, G. Maddaloni, G. Magliulo, C. Petrone, and A. Prota, "Shake table tests for the seismic fragility evaluation of hospital rooms," Earthquake Engineering \& Structural Dynamics, vol. 44, no. 1, pp. 23-40, 2015.

[34] J. A. Gatscher and S. R. Littler, "Dynamic testing of nonstructural components and equipment: seismic qualification and determination of functional performance limits," in Proceedings of the 14th World Conference on Earthquake Engineering, Beijing, China, October 2008.

[35] F. Nikfar and D. Konstantinidis, "Shake table investigation on the seismic performance of hospital equipment supported on wheels/casters," Earthquake Engineering \& Structural Dynamics, vol. 46, no. 2, pp. 243-266, 2017.

[36] C. Petrone, L. Di Sarno, G. Magliulo, and E. Cosenza, "Numerical modelling and fragility assessment of typical freestanding building contents," Bulletin of Earthquake Engineering, vol. 15, no. 4, pp. 1609-1633, 2017.

[37] R. Retamales, G. Mosqueda, A. Filiatrault, and A. Reinhorn, "Testing protocol for experimental seismic qualification of distributed nonstructural systems," Earthquake Spectra, vol. 27, no. 3, pp. 835-856, 2011.

[38] Ministero delle Infrastrutture e dei Trasporti, Ministero delle Infrastrutture e dei Trasporti, Circolare 21 gennaio 2019, n. 7 C.S.LL," in Istruzioni per l'applicazione dell' "Aggiornamento delle "Norme tecniche per le costruzioni"” di cui al decreto ministeriale 17 gennaio 2018Rome, Italy, 2019.

[39] Cen, EN 1998-1 Eurocode 8: Design Provisions for Earthquake Resistance of Structures, -Part 1: General Rules, European Committee for Standardization, Brussels, Belgium, 2004.

[40] L. Cavaleri and F. Di Trapani, "Cyclic response of masonry infilled RC frames: experimental results and simplified modeling," Soil Dynamics and Earthquake Engineering, vol. 65, pp. 224-242, 2014.

[41] S. Mazzoni, F. McKenna, M. H. Scott, and G. L. Fenves, OpenSees Command Language Manual, Pacific Earthquake Engineering Research (PEER) Center, Berkeley, CA, USA, 2006.

[42] G. A. Chang and J. B. Mander, Seismic Energy Based Fatigue Damage Ananlysis of Bridge Columns:Part 1-Evaluation of Seismic Capacity, NCEER Technical Report, NCEER-94-0006 State University of New York, Buffalo, N.Y, USA, 1994.

[43] PEER NGA-West Database, https://peer.berkeley.edu/ngawest available on-line:.

[44] N. Jayaram, T. Lin, and J. W. Baker, "A computationally efficient ground-motion selection algorithm for matching a target response spectrum mean and variance," Earthquake Spectra, vol. 27, no. 3, pp. 797-815, 2011.

[45] P. Fajfar and P. Gašperšič, "The N2 method for the seismic damage analysis of RC buildings," Earthquake Engineering \& Structural Dynamics, vol. 25, no. 1, pp. 31-46, 1996.

[46] Asce07, Minimum Design Loads for Buildings and Other Structures, American Society of Civil Engineers, Reston, VA, USA, 2016.

[47] Decreto legislativo 9 aprile 2008, Attuazione Dell'articolo 1 Della Legge 3 Agosto 2007, N. 123 Materia di tutela della salute e della sicurezza nei luoghi di lavoroGazzetta Ufficiale, Rome, Italy, 2008. 